\title{
Groundwater
}

\author{
Methods Note/
}

\section{An Integrated Laboratory Method to Measure and Verify Directional Hydraulic Conductivity in Fine-to-Medium Sandy Sediments}

\author{
by Jialiang Cai ${ }^{1}$, Thomas Taute ${ }^{2}$, Enrico Hamann ${ }^{2}$, and Michael Schneider ${ }^{2}$
}

\begin{abstract}
The constant-head permeameter test (CHPT) is widely used in sandy samples as a standard method in the laboratory to investigate hydraulic conductivity $(K)$. However, it neither can be used to consistently determine directional hydraulic conductivity (DHC) nor guarantee the comparability of measured $K$ values of samples with different sizes. Therefore, this paper proposes an integrated laboratory method, called modified CHPT (MCHPT), for the efficient determination and verification of consistent DHC values in fine-to-medium sandy sediments, based on a new methodological framework. A precise and standardized procedure for preparing the experimental setup of MCHPT was conducted, based on the integrated experimental setup of CHPT and tracer tests. Moreover, a formula was yielded for the time-optimized sample saturation control. In comparison with grain size-based methods, the validity of consistent $K_{\mathrm{h}}$ and $K_{\mathrm{v}}$ values determined by MCHPT was convincing.
\end{abstract}

\section{Introduction}

Hydraulic conductivity $(K)$ is one of the most important sediment properties in terms of hydrogeological issues; it controls many hydrological processes and usually directionally varies with space in a geologic formation. Knowledge of $K$ and its two-dimensional anisotropy, defined as the ratio of horizontal to vertical hydraulic conductivity $\left(K_{\mathrm{h}} / K_{\mathrm{v}}\right)$, is commonly considered crucial to meaningfully understand and quantify water flow and chemical transport in sediments. Therefore, it is essential to measure the directional parameter. However, one of the challenging tasks hydrogeologists face today is the high-resolution characterization of directional hydraulic conductivity (DHC) in sediments (Vienken and Dietrich 2011).

\footnotetext{
${ }^{1}$ Corresponding author: Institut für Geologische Wissenschaften, Freie Universität Berlin, 12249 Berlin, Germany; +49 030838 70629; fax: +49030838 70742; jialiang.cai@fu-berlin.de

${ }^{2}$ Institut für Geologische Wissenschaften, Freie Universität Berlin, 12249 Berlin, Germany.

Received August 2013, accepted November 2013.

(c) 2014, National Ground Water Association.

doi: $10.1111 /$ gwat.12156
}

A variety of laboratory and field methods used in sediments have been reported to yield approximations of $K$, including grain size analyses (Seelheim 1880; Hazen 1892; Terzaghi 1925; Carman 1937; Kozeny 1953; Hütte 1956; Beyer 1964; Köhler 1965; Kaubisch and Fischer 1985; Kaubisch 1986; Vukovic and Soro 1992; Kasenow 2002; Chapuis 2004), permeameter tests (Hvorslev 1951; Freeze and Cherry 1979; Todd and Mays 2005), slug and bail tests (Cooper et al. 1967; Bouwer and Rice 1976; Hyder et al. 1994; Butler 1998), pumping tests (Theis 1935; Cooper and Jacob 1946; Chow 1952; Neuman 1975; Moench 1995) and borehole flow-meter tests (Molz et al. 1994; Young and Pearson 1995; Molz and Melville 1996). However, comparison of the $K$ values obtained by diverse methods is difficult owing to the fact that determined $K$ values represent different spatial scales and, what is more important in our study, they all fail to measure DHC consistently. Grain size analyses deliver nondirectional $K$ values as the natural sediment structure is destroyed during the determination of grain size distribution, for example, the sieving process (Cheng and Chen 2007; Song et al. 2009). Owing to the induction of predominantly horizontal flow patterns, slug and bail tests, pumping tests, as well as borehole flow-meter tests can only estimate $K_{\mathrm{h}}$ 


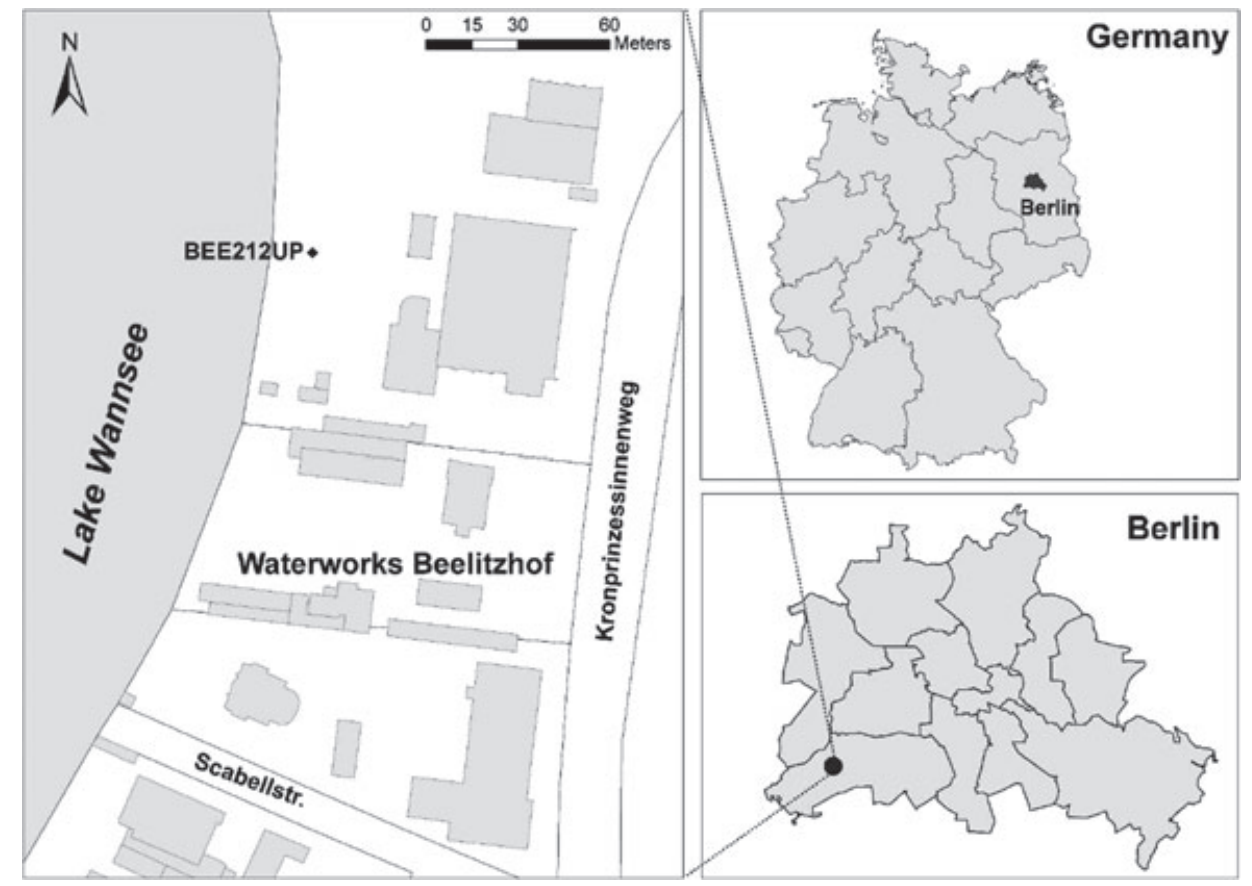

Figure 1. Location of study site and sampling point BEE212UP.

values (Paradis and Lefebvre 2013). Permeameter tests can optimally provide $K_{\mathrm{v}}$ and $K$ values in the case of undisturbed and disturbed samples respectively, while it is beyond their capacity to provide $K_{\mathrm{h}}$ values (Wojnar et al. 2013). Thus, an appropriate method for measuring DHC in sediments and therefore obtaining $K_{\mathrm{v}}$ and $K_{\mathrm{h}}$ values consistently is highly desirable.

Because of the fact that measuring DHC requires undisturbed samples, permeameter tests arise as an appropriate method. They have been demonstrated to be (1) suitable for a sample size of centimeters to decimeters (Wojnar et al. 2013), (2) reliable with regard to measurement precision (Paradis and Lefebvre 2013), (3) controllable over sample saturation (Madsen et al. 2008), and (4) economical with low-cost devices (Fallico et al. 2010).

Concerning sandy samples, the constant-head permeameter test (CHPT) is widely used as a standard method in the laboratory, based on the measurement of the onedimensional steady-state water flow through a sample with a constant hydraulic gradient and the direct application of the Darcy equation to investigate $K$ (Klute and Dirksen 1986; Xiang 1994). Considering sandy soils, the twocore method (Dabney and Selim 1987; Bathke and Cassel 1991; Dorner and Horn 2006; Petersen et al. 2008) and the modified cube method (Beckwith et al. 2003; Bagarello et al. 2009) are commonly used in CHPT for obtaining undisturbed samples to secure the values of DHC. However, both of these are only practical for sampling near-surface soil rather than at greater depths (Bagarello et al. 2009). Our previous investigations in fine-to-medium sandy sediments have shown that CHPT is still unsuitable for consistently determining the DHC of samples with different sizes. Moreover, a precise and standardized procedure for preparing the experimental setup has not yet been reported, for example for dimensioning the tubing to ensure laminar flow conditions, as required for a Darcy equation-based method. Hence, it is essential to modify CHPT to be able to measure DHC in fine-tomedium sandy sediments with variable sample sizes of centimeters to decimeters consistently.

The principal aim of this research, therefore, was to establish an integrated laboratory method, called modified CHPT (MCHPT), for the efficient determination and verification of consistent DHC values in fine-tomedium sandy sediments based on a new methodological framework. The specific objectives were to (1) develop a new method to obtain undisturbed core samples with several centimeters to decimeters in length, (2) modify the experimental setup and procedure of CHPT to determine consistent $K_{\mathrm{h}}$ and $K_{\mathrm{v}}$ values with different sample sizes, (3) validate the accuracy of the developed method and modifications, and (4) provide an efficient, precise, and applicable methodological framework of MCHPT for general determination and verification of DHC values in fine-to-medium sandy sediments.

\section{Sediment Sampling}

The samples were taken from a freshwater aquifer in southwestern Berlin, Germany (Figure 1). The geological conditions at the site are characterized by quaternary unconsolidated fluvio-glacial sandy sediments.

The borehole-drilling work was conducted at a depth of $170 \mathrm{~m}$ below the surface. The percussion drilling method (Urban 2002) was used to allow the retrieval of undisturbed core samples in liners with a diameter of $10 \mathrm{~cm}$ and a length of $1 \mathrm{~m}$. During the drilling work, the groundwater level was $\sim 3 \mathrm{~m}$ below the surface. Six 


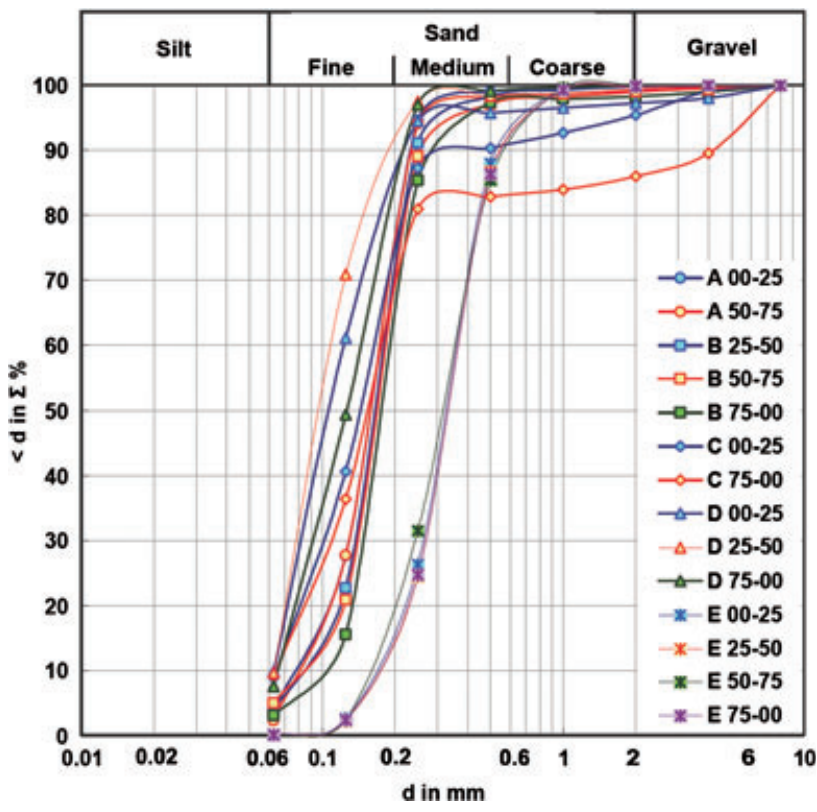

Figure 2. Grain size distribution of $25-\mathrm{cm}$ core samples (25CS). (1) A-F represent six 1-m undisturbed core samples from the depths of 111-112, 112-113, 113-114, 114-115, 147-148, and 148-149 $\mathrm{m}$ below the surface, respectively; (2) the numbers $0-25,25-50,50-75$, and $75-100$ mean a $25 \mathrm{CS}$ sample with a depth from 0 to 25,25 to 50,50 to 75 , and 75 to $100 \mathrm{~cm}$, respectively.

1-m-deep undisturbed core samples (A to F) from depths 111 to 112,112 to 113,113 to 114,114 to 115,147 to 148 , and 148 to $149 \mathrm{~m}$ below the surface were obtained. Meanwhile, the circulation drilling method (Urban 2002) was used to investigate the general sedimentary profile of these core samples by taking disturbed mixed cup samples of every meter, which showed that each 1-m core sample itself was without layering and could therefore be assumed to be homogenous. From the grain size analyses shown in Figure 2, core samples A, B, C, and D were dominated by fine sand, and $\mathrm{E}$ and $\mathrm{F}$ by medium sand.

\section{Principle and Applicability of CHPT}

In the experimental setup of CHPT (Figure 3), a core sample of length $(L)$ and a cross-sectional area $(A)$ are enclosed between two porous plates and sieves in a cylinder. A hydraulic constant-head differential $(H)$ is imposed across the sample of $L$, and the resulting flux of water is measured. A simple application of Darcy's law leads to the expression

$$
K=\frac{Q \times L}{A \times H}
$$

where $Q$ is the volumetric flow rate, measured as the volume of water $(V)$ that flows through the sample of $A$ in time $t$.

CHPT can be used with undisturbed or repacked core samples (Klute and Dirksen 1986). The sizes of core samples may vary. However, it is reasonably practical with diameters in the order of 2 to $10 \mathrm{~cm}$ and lengths of 5 to $25 \mathrm{~cm}$ for measurements in the laboratory (Klute and Dirksen 1986).

CHPT is best suited to sandy samples with $K$ values $>1.7 \times 10^{-6} \mathrm{~m} / \mathrm{s}\left(K_{\min }\right)$ based on the magnitudes of $K$ related to the sample materials as well as the appreciable measurement error of the volumetric flow rate (Klute 1965). Besides, it is necessary to restrict the hydraulic gradient $(i)$ to values less than 1 for applying the Darcy equation in sandy samples, because it should be valid when the inertial forces on the fluid are negligible compared to the viscous forces (Hubbert 1957; Klute and Dirksen 1986).

Owing to the fact that there is no standardized laboratory experimental setup and no quality check, the comparability between samples of different sizes as well as of different researchers cannot be guaranteed.

\section{Methodological Framework of MCHPT}

The methodological framework of MCHPT consists of four parts: (1) preparation and validation of undisturbed core samples, (2) determination and validation of $K_{\mathrm{v}}$ values, (3) adaptation of the experimental setup and procedure, and (4) determination and validation of $K_{\mathrm{h}}$ values (Figure 4).

\section{Preparation of Undisturbed Core Samples and Validation}

\section{Procedure}

Each 1-m undisturbed vertical core sample was cut through into four 25-cm core samples (25CS) (Figure 5). The 25CS samples including the core shields were taken for measuring $K_{\mathrm{v}}$.

To prepare samples for the determination of $K_{\mathrm{h}}$ values, the half core shields of the $25 \mathrm{CS}$ samples were horizontally cut off and removed without damaging the inner sediments. At that time the nonexistence of layering in all the $25 \mathrm{CS}$ samples for warranting their homogeneity could be verified. Then three horizontal cylindrical samples (6.5CS) were taken from each $25 \mathrm{CS}$ sample with a length of $6.5 \mathrm{~cm}$ and a diameter of $3.8 \mathrm{~cm}$ (Figure 5).

\section{Validation}

As Klute and Dirksen (1986) suggested, it is necessary to measure the bulk density $\left(\rho_{\mathrm{b}}\right)$, if repacked samples are to be used. Therefore, $\rho_{\mathrm{b}}$ values of the $6.5 \mathrm{CS}$ and $25 \mathrm{CS}$ samples were determined to validate whether the $6.5 \mathrm{CS}$ samples originating from the $25 \mathrm{CS}$ samples were intact.

The $\rho_{\mathrm{b}}$ is defined as the weight of the oven-dried mass $\left(m_{\mathrm{d}}\right)$ divided by its total volume $\left(V_{\mathrm{T}}\right)$

$$
\rho_{\mathrm{b}}=\frac{m_{\mathrm{d}}}{V_{\mathrm{T}}}
$$




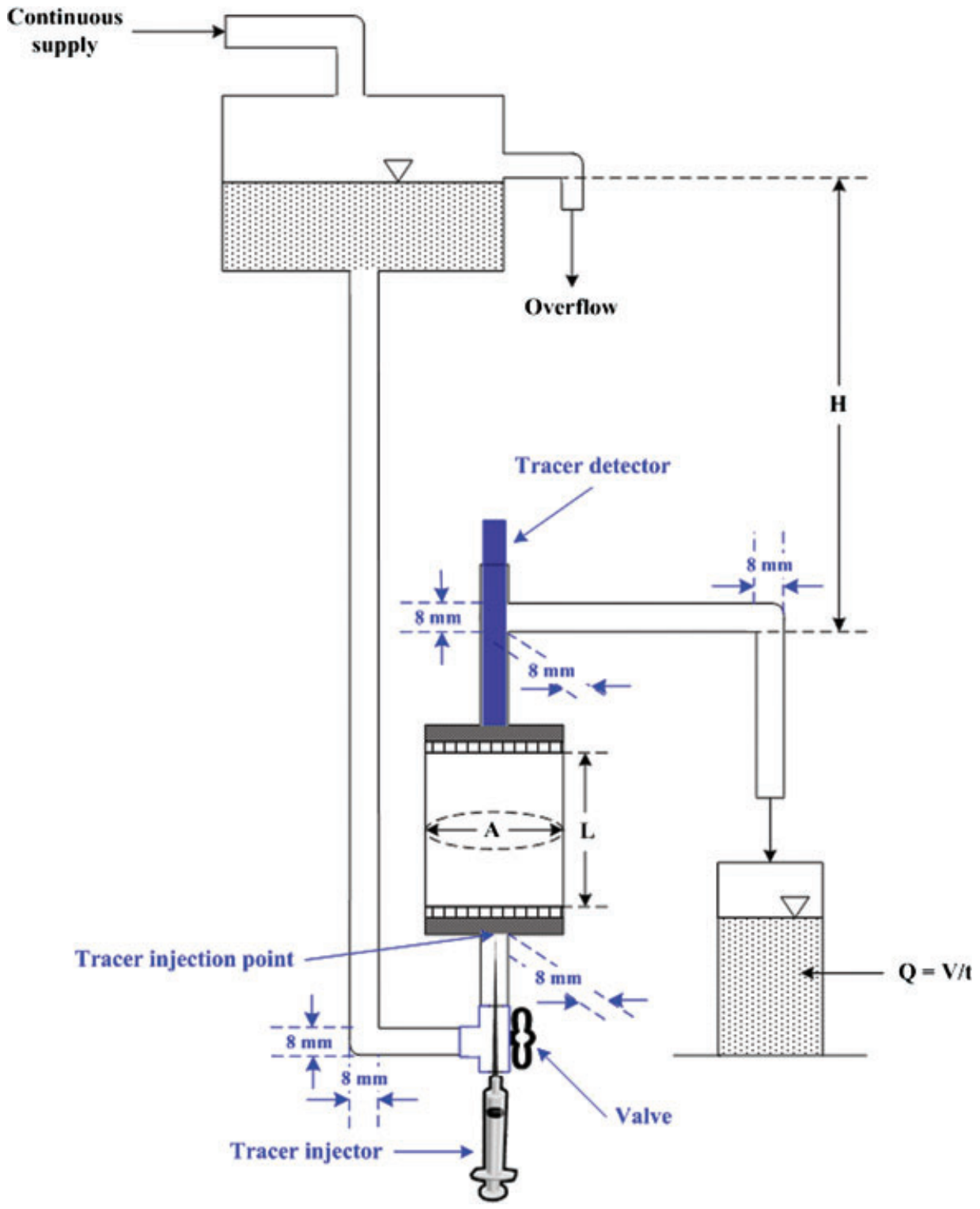

Figure 3. Experimental setup of constant-head permeameter test (CHPT) (black part) and integrated experimental setup of modified CHPT (MCHPT) and tracer test (black and blue part).

where

$$
m_{\mathrm{d}}=\left(m_{\mathrm{d}}+m_{\mathrm{b}}\right)-m_{\mathrm{b}}
$$

where $m_{b}$ is the weight of the empty dry bowl used to contain the mass for weighing; $V_{\mathrm{T}}$ is the total volume of the core sample, expressed as

$$
V_{\mathrm{T}}=\pi\left(\frac{D_{\mathrm{CS}}}{2}\right)^{2} \times L
$$

where $D_{\mathrm{CS}}$ is the diameter of the core sample.

Concerning the 25CS samples, two pieces of the core samples with a length of $5 \mathrm{~cm}$ from top and bottom were cut off. So they were two samples for measuring $\rho_{\mathrm{b}_{25 \mathrm{CS}}}$. Both the $6.5 \mathrm{CS}$ samples and the two portions from the 25CS samples were oven-dried at $105^{\circ} \mathrm{C}$ for $24 \mathrm{~h}$ to obtain $m_{\mathrm{d}}$ values for further calculation of $\rho_{\mathrm{b}}$ values.
Owing to the fact that the differences between the $\rho_{\mathrm{b}_{6.5 \mathrm{CS}}}$ value and the average value of two $\rho_{\mathrm{b}_{25 \mathrm{CS}}}$ values were $<1 \%$ (Table 1), it was demonstrated that intact $6.5 \mathrm{CS}$ samples with minimal disturbance were obtained.

\section{Determination and Validation of $K_{v}$ Values}

The measured $K_{\mathrm{v}}$ values were in the range between $5.1 \times 10^{-6}$ and $1.6 \times 10^{-4} \mathrm{~m} / \mathrm{s}$ (Figure 6).

On the basis of the applicability at the laboratory scale in the order of centimeters (Ptak et al. 2004), tracer tests were used to yield the values of effective porosity $\left(n_{\mathrm{e}}\right)$ of the $25 \mathrm{CS}$ samples by three parallel tests per sample for validation of $K_{\mathrm{v}}$ values. The experimental setup of the tracer tests was built into the CHPT system with a tracer injector and a detector. As tracer, $1 \mathrm{~mL}$ of $10 \mathrm{~g} / \mathrm{L}$ sodium chloride was used to monitor electrical conductance. 
Table 1

Bulk Density of a 6.5-cm Core Sample ( $\left.\rho_{\mathrm{b}_{6.5 \mathrm{CS}}}\right)$ Compared with Average Bulk Density of a 25-cm Core Sample $\left(\bar{\rho}_{\mathbf{b}_{25 \mathrm{CS}}}\right)$

\begin{tabular}{lcccccc}
\hline Sample & $\begin{array}{c}\boldsymbol{D} \\
(\mathbf{c m})\end{array}$ & $\begin{array}{c}\boldsymbol{L} \\
(\mathbf{c m})\end{array}$ & $\begin{array}{c}\boldsymbol{V}_{\mathbf{T}} \\
\left(\mathbf{c m}^{\mathbf{3}}\right)\end{array}$ & $\begin{array}{c}\boldsymbol{m}_{\mathbf{d}} \\
(\mathbf{g})\end{array}$ & $\begin{array}{c}\boldsymbol{\rho}_{\mathbf{b}} \\
\left(\mathbf{g} / \mathbf{c m}^{\mathbf{3}}\right)\end{array}$ & $\begin{array}{c}\overline{\boldsymbol{\rho}}_{\mathbf{b}} \\
\left(\mathbf{g} / \mathbf{c m}^{\mathbf{3}}\right)\end{array}$ \\
\hline Top sample from a 25-cm core sample & 10.0 & 5.0 & 392.70 & 524.48 & 1.34 & 1.34 \\
Bottom sample from the same 25-cm core sample & 10.0 & 5.0 & 392.70 & 530.17 & 1.35 & 1.35 \\
6.5-cm core sample & 3.8 & 6.5 & 73.72 & 99.31 & 1.35 & \\
\hline
\end{tabular}

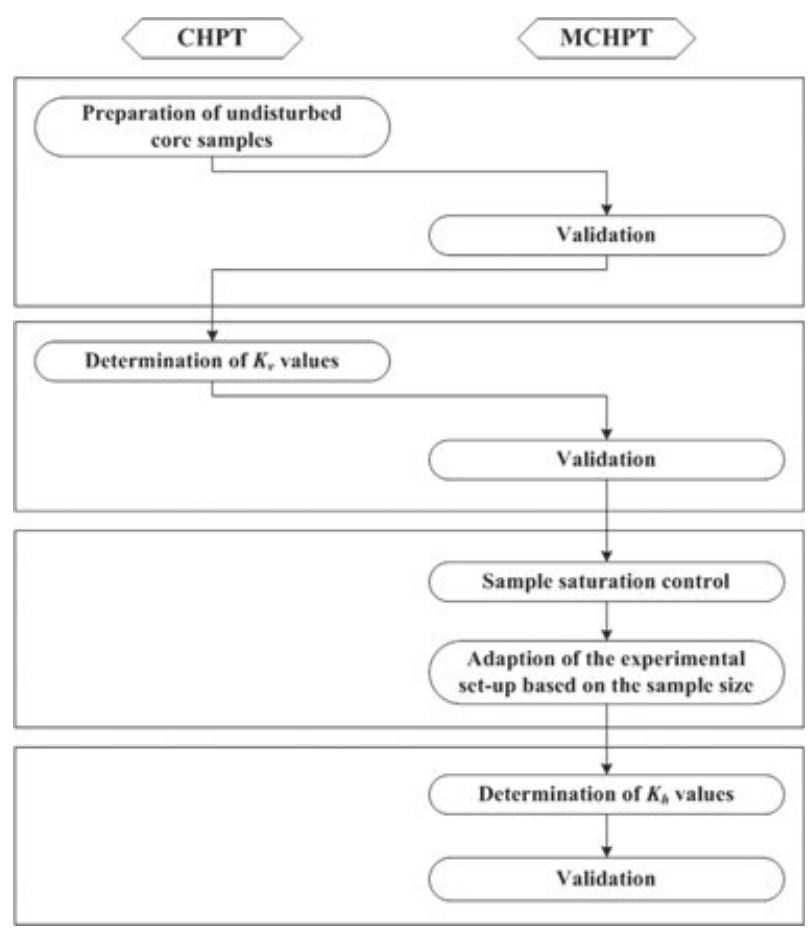

Figure 4. Methodological framework of modified constanthead permeameter test (MCHPT). from

According to Darcy's law, $n_{\mathrm{e}}$ values are calculated

$$
n_{\mathrm{e}}=\frac{K \times i}{v_{\mathrm{d}}}
$$

where $i$ is expressed as

$$
i=\frac{H}{L}
$$

and $v_{\mathrm{d}}$ is the distance velocity, defined as the tracer solution reaches distance $(x)$ between injection and detection through the core sample in time $(t)$; however, it is normally calculated from

$$
v_{\mathrm{d}}=\frac{v_{\mathrm{d}, \mathrm{dom}}+v_{\mathrm{d}, \mathrm{med}}}{2}
$$

where $v_{\mathrm{d}, \mathrm{dom}}$ is the dominant distance velocity obtained from the cumulative concentration-time-curve where tracer solution reaches the maximal concentration; and $v_{\mathrm{d}, \text { med }}$ is the medium distance velocity obtained from the cumulative concentration-time-curve where tracer solution reaches the concentration of 50\% (Langguth and Voigt 2004; Todd and Mays 2005).

Furthermore, the $n_{\mathrm{e}}$ values can be verified by the porosity $(n)$ that is closely related to $\rho_{\mathrm{b}}$ as

$$
n=1-\frac{\rho_{\mathrm{b}}}{\rho_{\mathrm{s}}}
$$

where $\rho_{\mathrm{s}}$ is the particle density and generally evaluated as $2.65 \mathrm{~g} / \mathrm{cm}^{3}$ for mineral soils and sediments (Vomocil 1965).

The range of $n$ values in fine-to-medium sand is 0.4 to 0.5 (Freeze and Cherry 1979), complying with geophysical borehole measurements in our observation well. So all $n_{\mathrm{e}}$ values must be $<0.5$; otherwise the determination of $K$ values is unconvincing.

Owing to the fact shown in Equation 5 that the validity of $n_{\mathrm{e}}$ values depends on that of $v_{\mathrm{d}}$ values, the trace solution should be precisely injected at the bottom of the cylinder and detected at its top (Figure 3). The $n_{\mathrm{e}_{25 \mathrm{cs}}}$ values were all $<0.5$ (Figure 7 ), which indicated that MCHPT was suitable for determining the $K_{\mathrm{v}}$ values of the 25CS samples.

\section{Adaption of the Experimental Setup and Procedure}

\section{Sample Saturation Control}

Owing to the fact that saturated hydraulic properties are intended to measure, it is obvious that sample saturation has to be guaranteed. However, the procedure of sample saturation can be time-consuming, because trapped air in the sediment pores tends to disappear only slowly as water passes through the sample (Klute and Dirksen 1986). Notwithstanding that Freeze and Cherry (1979) and Klute and Dirksen (1986) recommend de-aired water to ensure air is excluded from the CHPT system and a vacuum-wetting procedure, respectively, tap-water is commonly used to conduct CHPT for measuring $K$ in sandy sediments. To reach a time-optimized saturation point of samples, this procedure was modified by a control formula.

On the basis of all determined $K_{\mathrm{v}}$ and $n_{\mathrm{e}}$ values of the 25CS samples, this formula was developed to calculate the 


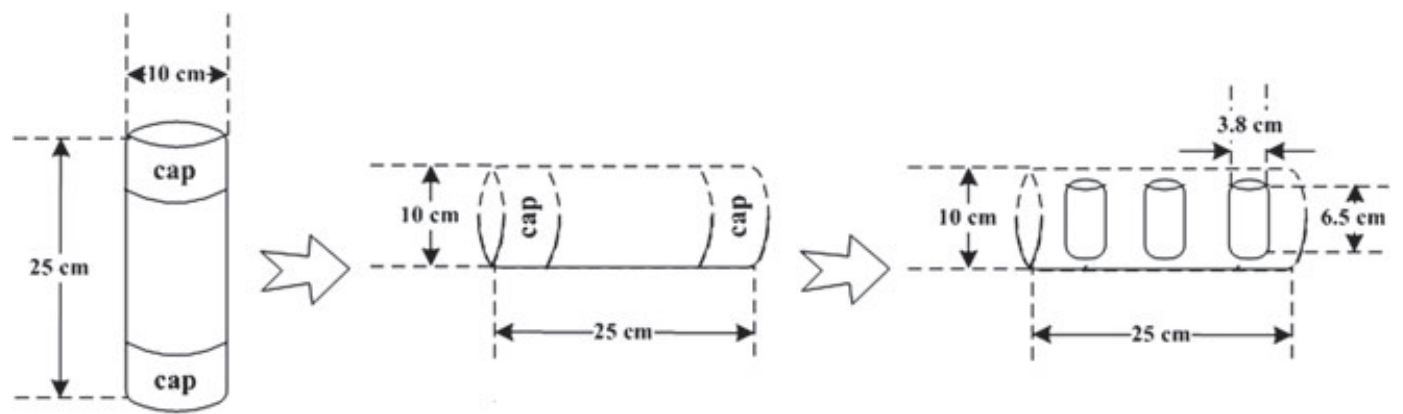

Figure 5. Procedure for obtaining undisturbed vertical and horizontal core samples for measuring directional hydraulic conductivities (DHC).

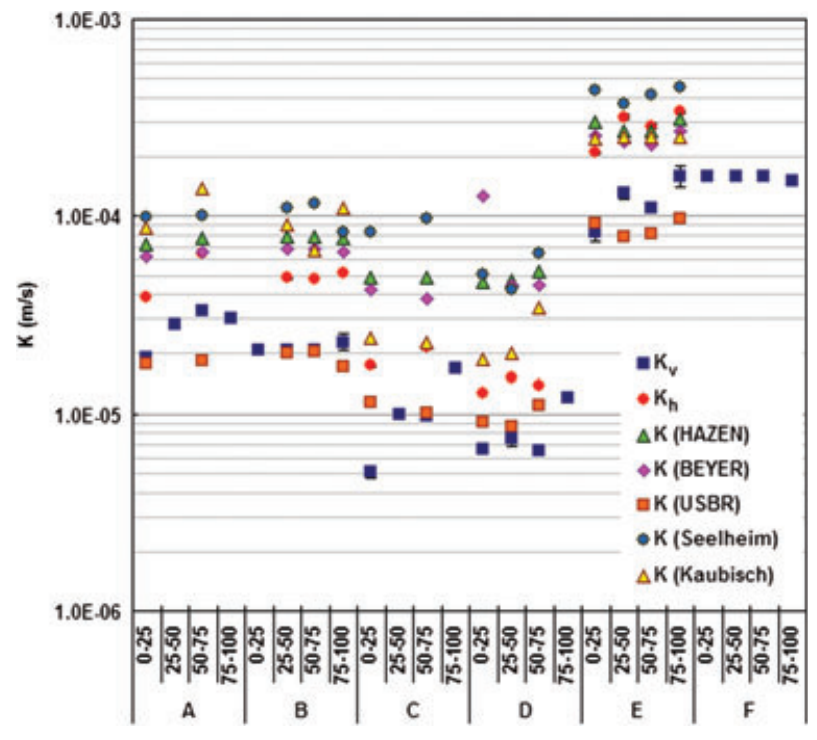

Figure 6. Vertical hydraulic conductivity $\left(K_{\mathrm{v}}\right)$ of $25-\mathrm{cm}$ core samples (25CS) and horizontal hydraulic conductivity $\left(K_{h}\right)$ of $6.5-\mathrm{cm}$ core samples $(6.5 \mathrm{CS})$ in comparison with hydraulic conductivity $(K)$ calculated by five empirical formulas. (1) A-F represent six 1-m undisturbed core samples from the depths of 111-112, 112-113, 113-114, 114-115, 147-148, and $148-149 \mathrm{~m}$ below the surface, respectively; (2) the numbers 0-25, 25-50, 50-75, and 75-100 mean a 25CS sample with a depth from 0 to 25,25 to 50,50 to 75 , and 75 to $100 \mathrm{~cm}$, respectively.

amount of water $\left(V_{\mathrm{w}}\right)$ continuously discharging through the pore volume of a core sample $\left(V_{\mathrm{s}}\right)$, that is, how many times $(P)$ water exchanged in $V_{\mathrm{s}}$ needed to reach saturated conditions of the core sample to avoid repeated measurements. This can be expressed as

$$
V_{\mathrm{w}}=V_{\mathrm{s}} \times P
$$

where

$$
V_{\mathrm{s}}=V_{\mathrm{T}} \times n_{\mathrm{e}}
$$

As a result, uniform $K_{\mathrm{v}}$ values of the $25 \mathrm{CS}$ samples were obtained after 60 pore volumes were exchanged (Figure 8), so $V_{\mathrm{w}}$ for determining the saturated $K_{\mathrm{h}}$ values of the $6.5 \mathrm{CS}$ samples was quantified as $3.5 \mathrm{~L}$ by using

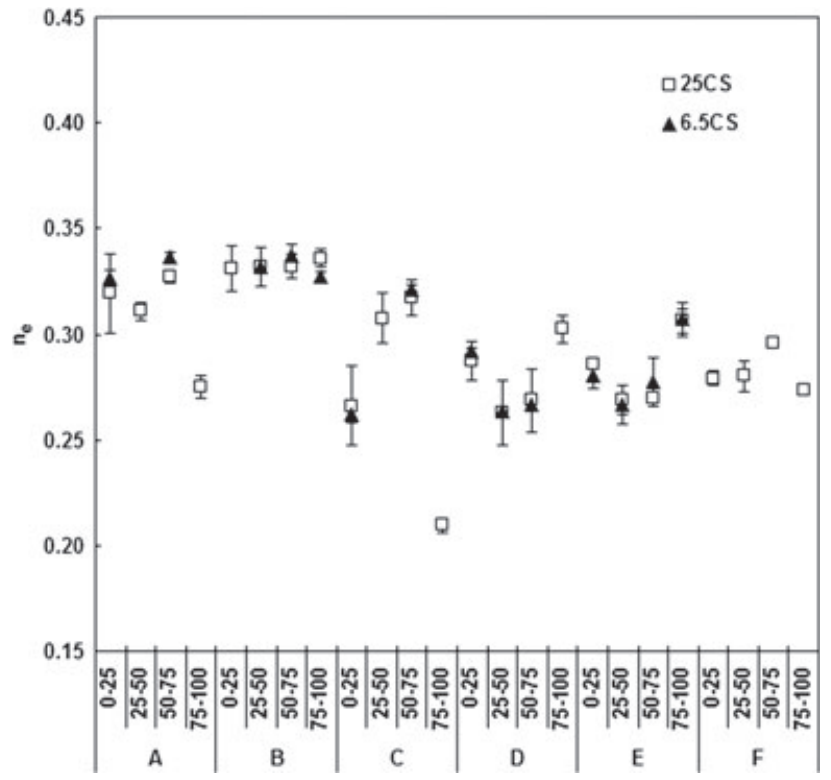

Figure 7. Effective porosity $\left(n_{\mathrm{e}}\right)$ of $6.5-\mathrm{cm}$ core samples (6.5CS) and $25-\mathrm{cm}$ core samples $(25 \mathrm{CS})$. (1) A-F represent six 1-m undisturbed core samples from the depths of 111-112, 112-113, 113-114, 114-115, 147-148, and 148-149 $\mathrm{m}$ below the surface respectively; (2) the numbers $0-25,25-50,50-75$, and 75-100 mean a 25CS sample with a depth from 0 to 25,25 to 50,50 to 75 , and 75 to $100 \mathrm{~cm}$, respectively.

60 times with an assumed generic maximum $n_{\mathrm{e}}$ value in fine-to-medium sand of 0.5 .

\section{Adaption of the Experimental Setup Based on the Sample Size}

First of all, owing to the small size of the 6.5CS samples compared with previous samples used in CHPT, it was necessary to ensure that the $K$ values of the experimental setup ( $\left.K_{\text {setup }}\right)$ were greater than the $K$ values of the samples $\left(K_{\text {sample }}\right)$. For that reason, a hollow cylinder with the same size as the 6.5CS samples was taken to measure $K_{\text {setup }}$, that is, only water continuously ran through the CHPT system. The $K_{\text {setup }}$ values (Figure 9a) were far greater than the largest $K$ values determined by different methods (Figure 6), which indicated that the 


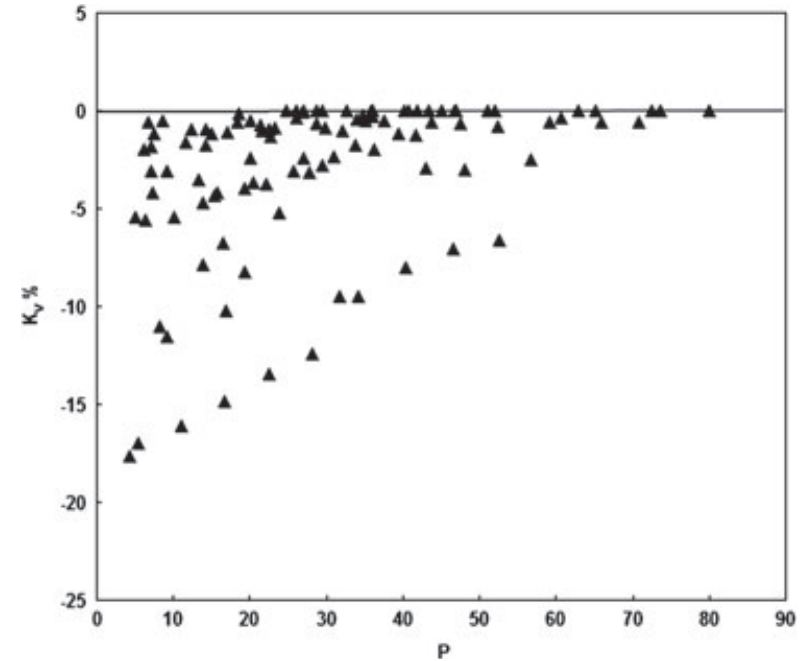

Figure 8. Variation of vertical hydraulic conductivity $\left(K_{\mathrm{V}} \%\right)$ to reach a saturation point of $25-\mathrm{cm}$ core samples in relation to times $(P)$ of water exchanges in the volume of core sample space. $K_{\mathrm{v}} \%=\frac{K_{\mathrm{v}, i}-K_{\mathrm{v}, \mathrm{s}}}{K_{\mathrm{v}, \mathrm{s}}} \times 100 \%$ where $K_{\mathrm{v}, i}$ is unsaturated $K_{\mathrm{v}}$ and $K_{\mathrm{v}, \mathrm{s}}$ is saturated $K_{v}$.

6.5CS samples were applicable in the experimental setup of MCHPT.

In the second place, $K$ values should be constant at different $i$, because there is a linear correlation of $Q$ and $i$ according to Darcy's law. However, the $K$ and $Q$ values at different $i$ shown in Figure 9 were inconsistent with this statement. Klute and Dirksen (1986) commented that the resulting $Q$ values will be less than those predicted by the Darcy equation, if $i$ is too large. As noted, $i$ had to be $<1$ to ensure the validity of the Darcy equation applied to the 6.5CS samples.

Third, the upper limit on the range of validity of Darcy's law is much more practically important, because Darcy's law is only valid at laminar flow conditions and

(a)

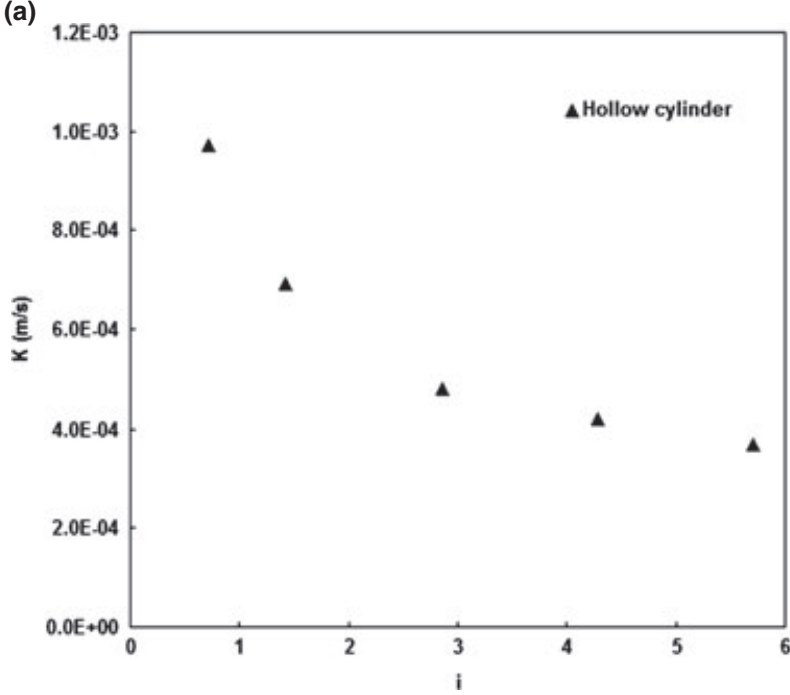

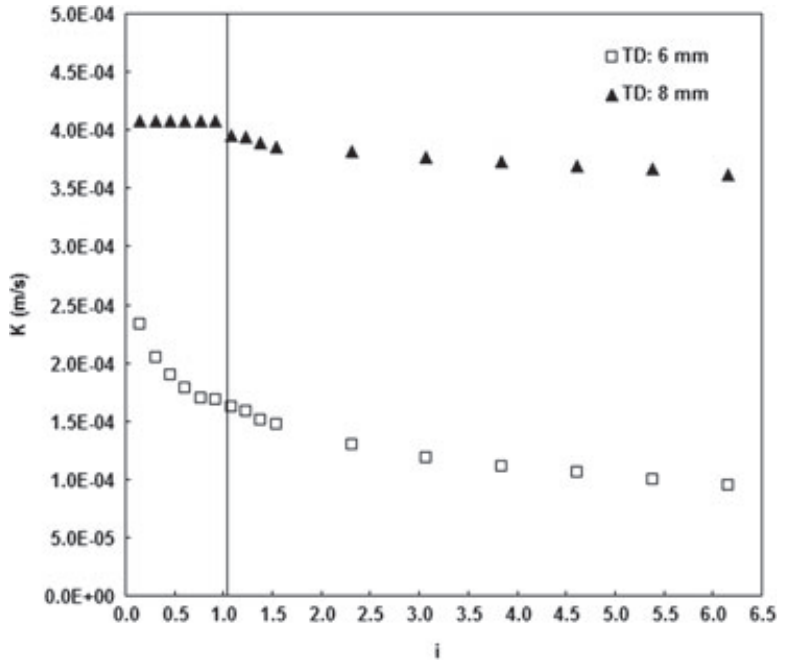

Figure 10. Hydraulic conductivity $(K)$ of glass beads in a cylinder with the same size as $6.5-\mathrm{cm}$ core samples $(6.5 \mathrm{CS})$ at different hydraulic gradients $(i)$ with tubing diameters (TD) of 6 and $8 \mathrm{~mm}$.

breaks therefore down at very high flow rates (Bear 1972; Todd and Mays 2005). To distinguish between laminar and turbulent flow, the Reynolds number $\left(R_{e}\right)$, a dimensionless number that expresses the ratio of inertial to viscous forces, is consequently widely used in fluid mechanics (Falkovich 2011). For flow through porous media in a pipe, $R_{e}$ is generally defined as

$$
R_{e}=\frac{\rho \times Q \times D_{\mathrm{P}}}{\mu \times A}
$$

where $\rho$ is the fluid density; $\mu$ is the dynamic viscosity; and $D_{\mathrm{P}}$ is the pipe diameter (Falkovich 2011).

Darcy's law is valid as long as $R_{e}$ is in the range of values between 1 and 10, where all flow is laminar (Bear 1972; Freeze and Cherry 1979). Moreover, the tubing

(b)

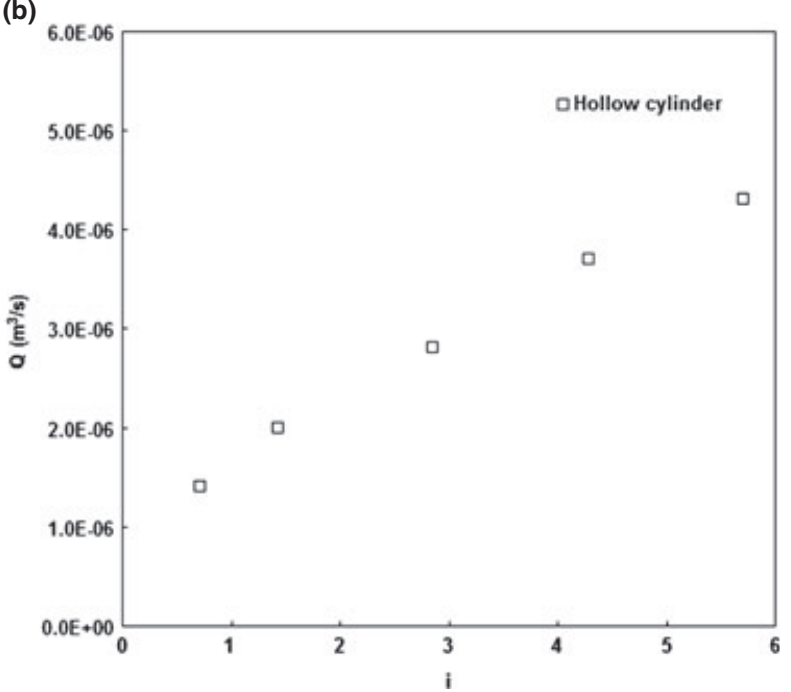

Figure 9. Hydraulic conductivity $(K)$ (a) and volumetric flow rate $(Q)$ (b) of a hollow cylinder with the same size as 6.5-cm core samples (6.5CS) at different hydraulic gradients $(i)$. 


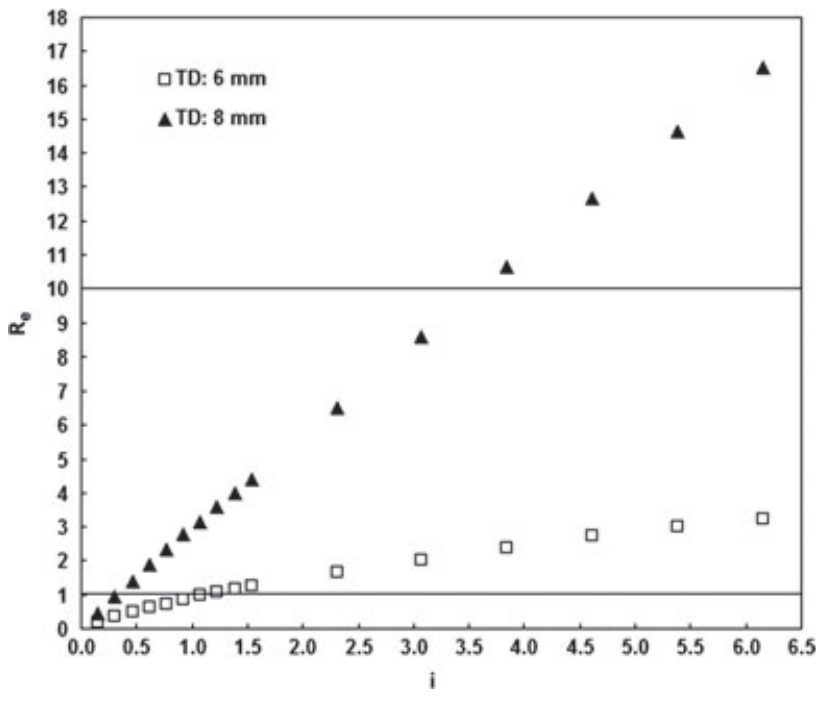

Figure 11. Reynolds number $\left(\boldsymbol{R}_{e}\right)$ for flow through glass beads in tubing with diameters (TD) of 6 and $8 \mathrm{~mm}$ at different hydraulic gradients $(i)$.

diameter has been found to have an important effect on the superficial friction (Govier and Short 1958). Therefore, it would be expected to obtain constant $K$ values at restricted different $i$ by modifying the tubing diameter on the premise of fitting the CHPT system.

To get an idea of the maximum $i$ at certain tubing diameters, homogenous glass beads (GB) with diameters of 1.00 to $1.30 \mathrm{~mm}$, classified by sedimentological criteria as coarse sand, were used as testing samples for controlling the measurement precision. The tubing diameter was modified from 6 to $8 \mathrm{~mm}$ (Figure 3). The $K_{\mathrm{GB}}$ values (Figure 10) were less than the $K_{\text {setup }}$ values (Figure 9), which supports the reliability of the method. The $K_{\mathrm{GB}}$ values determined by CHPT with modified tubing of greater diameter remained constant at different $i$ of values from 0.15 to 0.92 . In this range of $i$, the $R_{e}$ values in the tubing with a diameter of $6 \mathrm{~mm}$ were all $<1$, while the $R_{e}$ values in the tubing with a diameter of $8 \mathrm{~mm}$ were in the range between 1 and 10 at different $i$ of values from 0.46 to 0.92 (Figure 11). That implies that the tubing diameter should be at least $8 \mathrm{~mm}$ to guarantee Darcy flow conditions.

Consequently, the $K_{\mathrm{h}}$ values of the $6.5 \mathrm{CS}$ samples can be determined at $H$ of $6 \mathrm{~cm}$ by MCHPT.

\section{Determination and Validation of $K_{\mathrm{h}}$ Values}

To demonstrate that MCHPT is suitable for determining the $K_{\mathrm{h}}$ values of the $6.5 \mathrm{CS}$ samples, these values and the $n_{\mathrm{e}_{6.5 \mathrm{cs}}}$ values were checked. The $K_{\mathrm{h}}$ values were in the range between $1.3 \times 10^{-5}$ and $3.4 \times 10^{-4} \mathrm{~m} / \mathrm{s}$ (Figure 6), and therefore were greater than the $K_{\min }$ value of $1.7 \times 10^{-6} \mathrm{~m} / \mathrm{s}$ and less than the $K_{\text {setup }}$ value at $H$ of $6 \mathrm{~cm}$ of $\sim 8.0 \times 10^{-4} \mathrm{~m} / \mathrm{s}$. Meanwhile, the $n_{\mathrm{e}_{6.5 \mathrm{ss}}}$ values were all $<0.5$ (Figure 7 ). Thus, the $K_{\mathrm{h}}$ values determined by MCHPT were convincing.

\section{Comparison of MCPHT with Grain Size-Based Methods}

As noted, $K$ values estimated by sieving tests represent neither $K_{\mathrm{h}}$ nor $K_{\mathrm{v}}$ values. However, Vienken and Dietrich (2011) pointed out that $K$ values from sieving tests would likely be less than $K_{\mathrm{h}}$ values but greater than $K_{\mathrm{v}}$ values. This only applies for homogenous samples without layering, as in our study. Therefore, sieving tests could be used to validate the consistency of $K_{\mathrm{h}}$ and $K_{\mathrm{v}}$ values.

Numerous empirical and semiempirical formulas can be used to calculate $K$ values from grain size distribution performed by sieving tests. Some of them, such as the Kozeny-Köhler formula and the Terzaghi formula, have large uncertainty in the calculation of $K$ values due to the estimation of $n$ (Vienken and Dietrich 2011). So the empirical formulas listed in Table 2 were used to conduct a comprehensive assessment in fine-to-medium sandy sediments.

After determination of $K_{\mathrm{h}}$ values by MCHPT, the sieving samples were collected from the 25CS samples, taken as a basis for preparation of the 6.5CS samples,

Table 2

Summary of Applied Empirical Formulas for Calculating Hydraulic Conductivity $(K)$ (After Vienken and Dietrich [2011])

\begin{tabular}{|c|c|c|c|c|c|}
\hline Name & Formula & $K$ in & $\begin{array}{l}\text { Relevant } \\
\text { Parameter }\end{array}$ & $\begin{array}{l}\text { Application } \\
\text { Range }\end{array}$ & References \\
\hline Hazen & $\begin{array}{l}K=C_{\mathrm{H}} \times d_{10}^{2} \times(0.7+0.03 \times T) \\
T=\text { temperature } \\
C_{\mathrm{H}}=1000(\text { coefficient })\end{array}$ & $\mathrm{m} / \mathrm{d}$ & $d_{10}$ in $\mathrm{mm}$ & $\begin{array}{l}U<5 \\
0.1<d_{10}<3 \mathrm{~mm}\end{array}$ & $\begin{array}{l}\text { Hazen (1892) } \\
\text { Chapuis (2004) }\end{array}$ \\
\hline Beyer & $\begin{array}{l}K=C_{\mathrm{B}} \times d_{10}^{2} \\
C_{\mathrm{B}}=\log \frac{500}{U}\end{array}$ & $\mathrm{~m} / \mathrm{s}$ & $d_{10}$ in $\mathrm{mm}$ & $\begin{array}{l}U<20 \\
0.06<d_{10}<0.6 \mathrm{~mm}\end{array}$ & $\begin{array}{l}\text { Beyer (1964) } \\
\text { Vukovic and Soro (1992) }\end{array}$ \\
\hline USBR & $K=0.0036 \times d_{20}^{2.3}$ & $\mathrm{~m} / \mathrm{s}$ & $d_{20}$ in $\mathrm{mm}$ & $U<5$ & Vukovic and Soro (1992) \\
\hline Seelheim & $K=0.00357 \times d_{50}^{2}$ & $\mathrm{~m} / \mathrm{s}$ & $d_{50}$ in $\mathrm{mm}$ & - & Seelheim (1880) \\
\hline Kaubish & $K=10^{0.0005 P^{2}-0.12 P-3.59}$ & $\mathrm{~m} / \mathrm{s}$ & $P<0.06 \mathrm{~mm}$ in $\%$ & $10 \%<P<60 \%$ & $\begin{array}{l}\text { Kaubisch and Fischer (1985) } \\
\text { Kaubisch (1986) }\end{array}$ \\
\hline
\end{tabular}




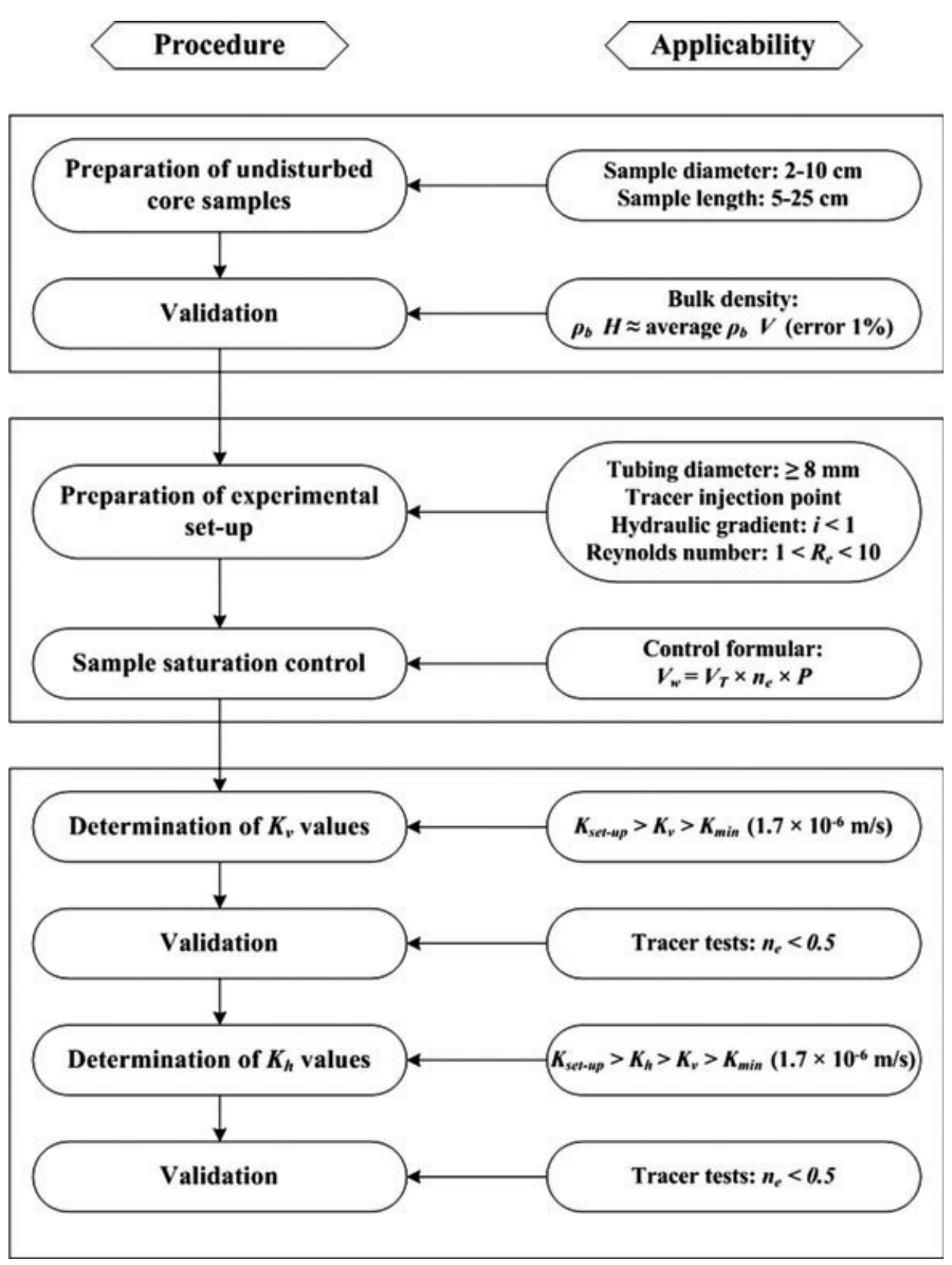

Figure 12. General methodological framework of modified constant-head permeameter test (MCHPT) for measuring and verifying directional hydraulic conductivity (DHC) in fine-to-medium sandy sediments.

and mixed with the three parallel 6.5CS samples. The specific procedure was performed according to Langguth and Voigt (2004).

All the $K_{\mathrm{h}}$ values were on average $\sim 2.3$ times greater than $K_{\mathrm{v}}$ values (Figure 6 ). For medium sandy sediments, the $K_{\text {Hazen }}, K_{\text {Beyer }}$, and $K_{\text {kaubisch }}$ values were less than the $K_{\mathrm{h}}$ values and greater than the $K_{\mathrm{v}}$ values. However, the $K_{\mathrm{USBR}}$ values were within the range between $K_{\mathrm{h}}$ and $K_{\mathrm{v}}$ values in fine sandy sediments. So DHC values would depend on $d_{10}$ or lower values in medium sandy sediments, but depend on $d_{20}$ in fine sandy sediments. This may be the reason why the DHC values in medium sandy sediments were greater than those in fine sandy sediments. Consequently, the validity of consistent $K_{\mathrm{h}}$ and $K_{\mathrm{v}}$ values was convincing.

\section{Summary and Conclusions}

This research established an integrated laboratory method, called modified CHPT (MCHPT), for the efficient determination and verification of consistent DHC values in fine-to-medium sandy sediments based on a new methodological framework. The key findings are summarized as follows:

- Undisturbed 25CS and 6.5CS samples were obtained for measuring $K_{\mathrm{v}}$ and $K_{\mathrm{h}}$ respectively by a newly developed method. The integrity of the 6.5CS samples from the 25CS samples was validated by bulk density, which indicated that the differences between the $\rho_{\mathrm{b}_{65} .5 \mathrm{CS}}$ value and the average value of two $\rho_{\mathrm{b}_{25 \mathrm{CS}}}$ values were $<1 \%$. 
- A precise and standardized procedure for preparing the experimental setup of MCHPT was conducted based on an integrated experimental setup of CHPT and tracer tests by modifying the outer tubing diameter of $8 \mathrm{~mm}$ and the tracer injection point for the valid applicability of the Darcy equation. Moreover, a formula (Equation 9) was provided for the timeoptimized control of sample saturation.

- The determination of $K_{\mathrm{h}}$ and $K_{\mathrm{v}}$ values showed that all the $K_{\mathrm{h}}$ values were on average $\sim 2.3$ times greater than the $K_{\mathrm{v}}$ values, and both of them were greater than the $K_{\min }$ value but less than the $K_{\text {setup }}$ value. They were validated by tracer tests with $n_{\mathrm{e}}$ values $<0.5$.

- In comparison with grain size-based methods, the validity of consistent $K_{\mathrm{h}}$ and $K_{\mathrm{v}}$ values determined by MCHPT was convincing.

Overall, an efficient, precise, and applicable methodological framework of MCHPT for the general determination and verification of DHC values in fine-to-medium sandy sediments can be obtained for further investigation (Figure 12).

\section{Acknowledgments}

We sincerely thank C. Menz, U. Maiwald, M. Gröschke, Dr. C. Sprenger, Dr. M. Ma, and F. Hecht for field sampling and laboratory support, as well as Dr. A. Winkler and two anonymous reviewers for their constructive comments. We also thank Prof. I. C. Bruce (Zhejiang University) for reading the manuscript. The first author is sponsored by the ERASMUS MUNDUS External Cooperation Window Scholarship at Freie Universität Berlin (Project Lund, Lot 14a-China).

\section{References}

Bagarello, V., S. Sferlazza, and A. Sgroi. 2009. Testing laboratory methods to determine the anisotropy of saturated hydraulic conductivity in a sandy-loam soil. Geoderma 154, no. 1-2: 52-58.

Bathke, G.R., and D.K. Cassel. 1991. Anisotropic variation of profile characteristics and saturated hydraulic conductivity in an Ultisol landscape. Soil Science Society of America Journal 55, no. 2: 333-339.

Bear, J. 1972. Dynamics of Fluids in Porous Media. New York: American Elsevier.

Beckwith, C.W., A.J. Baird, and A.L. Heathwaite. 2003. Anisotropy and depth-related heterogeneity of hydraulic conductivity in a bog peat. I: Laboratory measurements. Hydrological Processes 17, no. 1: 89-101.

Beyer, W. 1964. Zur Bestimmung der Wasserdurchlässigkeit von Kiesen und Sanden aus der Kornverteilungskurve. Wasserwirtschaft Wassertechnik 14, no. 6: 165-168.

Bouwer, H., and R.C. Rice. 1976. Slug test for determining hydraulic conductivity of unconfined aquifers with completely or partially penetrating wells. Water Resources Research 12, no. 3: 423-428.

Butler, J.J. 1998. The Design, Performance, and Analysis of Slug Tests, 1st ed. Boca Raton, Florida: Lewis Publishers.

Carman, P. 1937. Fluid flow through granular beds. Transactions-Institution of Chemical Engineeres 15: $150-166$.
Chapuis, R.P. 2004. Predicting the saturated hydraulic conductivity of sand and gravel using effective diameter and void ratio. Canadian Geotechnical Journal 41, no. 5: 787-795.

Cheng, C., and X. Chen. 2007. Evaluation of methods for determination of hydraulic properties in an aquifer-aquitard system hydrologically connected to a river. Hydrogeology Journal 15, no. 4: 669-678.

Chow, V.T. 1952. On the determination of transmissibility and storage coefficients from pumping test data. Transactions, American Geophysical Union 33: 397-404.

Cooper, H.H., J.D. Bredehoe, and I.S. Papadopu. 1967. Response of a finite-diameter well to an instantaneous charge of water. Water Resources Research 3, no. 1: 263-269.

Cooper, H. Jr., and C. Jacob. 1946. A generalized graphical method for evaluating formation constants and summarizing well-field history. Transactions, American Geophysical Union 27: 526-534.

Dabney, S.M., and H.M. Selim. 1987. Anisotropy of a fragipan soil - vertical vs horizontal hydraulic conductivity. Soil Science Society of America Journal 51, no. 1: 3-6.

Dorner, J., and R. Horn. 2006. Anisotropy of pore functions in structured stagnic luvisols in the Weichselian moraine region in N Germany. Journal of Plant Nutrition and Soil Science-Zeitschrift Fur Pflanzenernahrung Und Bodenkunde 169, no. 2: 213-220.

Falkovich, G. 2011. Fluid Mechanics: A Short Course for Physicists. Cambridge, England: Cambridge University Press.

Fallico, C., S. De Bartolo, S. Troisi, and M. Veltri. 2010. Scaling analysis of hydraulic conductivity and porosity on a sandy medium of an unconfined aquifer reproduced in the laboratory. Geoderma 160, no. 1: 3-12.

Freeze, R.A., and J.A. Cherry. 1979. Groundwater. Englewood Cliffs, New Jersey: Prentice-Hall, Inc.

Govier, G., and W.L. Short. 1958. The upward vertical flow of air-water mixtures: II. Effect of tubing diameter on flowpattern, holdup and pressure drop. The Canadian Journal of Chemical Engineering 36, no. 5: 195-202.

Hazen, A. 1892. Some Physical Properties of Sands and Gravels: With Special Reference to Their Use in Filtration. 24th Annual Report of the State Board of Health of Massachusetts.

Hubbert, M.K. 1957. Darcy's law and the field equations of the flow of underground fluids. Hydrological Sciences Journal 2, no. 1: 23-59.

Hütte, A.V. 1956. Des Ingenieurs Taschenbuch. Band 3 Bautech$n i k, 28$ th ed. Berlin, Germany: Verlag von Wilhelm Ernst and Sohn.

Hvorslev, M. 1951. Time Lag and Soil Permeability in GroundWater Observations. Vicksburg, Mississippi: US Army Corps of Engineers.

Hyder, Z., J.J. Butler, C.D. Mcelwee, and W.Z. Liu. 1994 Slug tests in partially penetrating wells. Water Resources Research 30, no. 11: 2945-2957.

Kasenow, M. 2002. Determination of hydraulic conductivity from grain size analysis. Littleton, Colorado: Water Resources Publication, LLC.

Kaubisch, M. 1986. Zur indirekten Ermittlung hydrogeologischer Kennwerte von Kippenkomplexen, dargestellt am Beispiel des Braunkohlenbergbaus. Ph.D. diss., Bergakademie Freiberg.

Kaubisch, M., and M. Fischer. 1985. Zur Berechnung des Filtrationskoeffizienten in Tagebaukippen. Teil 3: Ermittlung des Filtrationskoeffizienten für schluffige Feinsande aus Mischbodenkippen durch Korngrößenanalysen. Neue Bergbautechnik 15: 142-143.

Klute, A. 1965. Laboratory measurement of hydraulic conductivity of saturated soil. In Methods of Soil Analysis. Part 1. Physical and Mineralogical Properties, Including Statistics of Measurement and Sampling, ed. C.A. Black, 
210-221. Madison, Wisconsin: American Society of Agronomy.

Klute, A., and C. Dirksen. 1986. Hydraulic conductivity and diffusivity: Laboratory methods. In Methods of Soil Analysis: Part 1-Physical and Mineralogical Methods, ed. A. Klute, 687-734. Madison, Wisconsin: American Society of Agronomy.

Köhler, H. 1965. Ein kombinierendes Verfahren zur Bestimmung des Durchlässigkeitsbeiwertes von Sand-und Kiesgemischen für Wasser aus Siebproben. Bergbautechnik 15: $338-342$.

Kozeny, J. 1953. Hydraulik : Ihre Grundlagen und Praktische Anwendung. Wien, Austria: Springer.

Langguth, H.-R., and R. Voigt. 2004. Hydrogeologische Methoden. 2., überarb. und erw, Aufl. ed. Berlin, Germany: Springer.

Madsen, M.D., D.G. Chandler, and W.D. Reynolds. 2008. Accounting for bias and boundary condition effects on measurements of saturated core hydraulic conductivity. Soil Science Society of America Journal 72, no. 3: $750-757$.

Moench, A.F. 1995. Combining the Neuman and Boulton models for flow to a well in an unconfined aquifer. Ground Water 33, no. 3: 378-384.

Molz, F.J., and J.G. Melville. 1996. Combined use of flowmeter and time-drawdown data to estimate hydraulic conductivities in layered aquifer systems - Discussion. Ground Water 34, no. 5: 770-770.

Molz, F.J., G.K. Boman, S.C. Young, and W.R. Waldrop. 1994. Borehole flowmeters - Field application and data-analysis. Journal of Hydrology 163, no. 3-4: 347-371.

Neuman, S.P. 1975. Analysis of pumping test data from anisotropic unconfined aquifers considering delayed gravity response. Water Resources Research 11, no. 2: 329-342.

Paradis, D., and R. Lefebvre. 2013. Single-well interference slug tests to assess the vertical hydraulic conductivity of unconsolidated aquifers. Journal of Hydrology 478: $102-118$.

Petersen, C., A. Trautner, and S. Hansen. 2008. Spatio-temporal variation of anisotropy of saturated hydraulic conductivity in a tilled sandy loam soil. Soil and Tillage Research 100, no. 1-2: $108-113$.
Ptak, T., M. Piepenbrink, and E. Martac. 2004. Tracer tests for the investigation of heterogeneous porous media and stochastic modelling of flow and transport-A review of some recent developments. Journal of Hydrology 294, no. 1-3: $122-163$.

Seelheim, F. 1880. Methoden zur Bestimmung der Durchlässigkeit des Bodens. Analytical and Bioanalytical Chemistry 19, no. 1: 387-418.

Song, J., X. Chen, C. Cheng, D. Wang, S. Lackey, and Z. Xu. 2009. Feasibility of grain-size analysis methods for determination of vertical hydraulic conductivity of streambeds. Journal of Hydrology 375, no. 3-4: 428-437.

Terzaghi, K. 1925. Erdbaumechanik auf Bodenphysikalischer Grundlage. Leipzig, Germany: Deuticke.

Theis, C.V. 1935. The relation between the lowering of the piezometric surface and the rate and duration of discharge of a well using ground-water storage. Transactions, American Geophysical Union 16: 519-524.

Todd, D.K., and L.W. Mays. 2005. Groundwater Hydrology, 3rd ed. Hoboken, New Jersey: Wiley.

Urban, D. 2002. Arbeitshilfen für den Brunnenbauer: Brunnenbohrtechnik. Bonn, Germany: Wirtschafts- und Verlagsgesellschaft Gas und Wasser mbH.

Vienken, T., and P. Dietrich. 2011. Field evaluation of methods for determining hydraulic conductivity from grain size data. Journal of Hydrology 400, no. 1-2: 58-71.

Vomocil, J.A. 1965. Porosity. In Methods of Soil Analysis. Part 1. Physical and Mineralogical Properties, Including Statistics of Measurement and Sampling, ed. C.A. Black, 299-314. Madison, Wisconsin: American Society of Agronomy.

Vukovic, M., and A. Soro. 1992. Determination of Hydraulic Conductivity of Porous Media from Grain-Size Distribution. Littleton, Colorado: Water Resources Publication, LLC.

Wojnar, A.J., S. Mutiti, and J. Levy. 2013. Assessment of geophysical surveys as a tool to estimate riverbed hydraulic conductivity. Journal of Hydrology 482: 40-56.

Xiang, J.N. 1994. Improvements in evaluating constant-head permeameter test data. Journal of Hydrology 162, no. 1-2: 77-97.

Young, S.C., and H.S. Pearson. 1995. The electromagnetic borehole flowmeter: Description and application. Ground Water Monitoring \& Remediation 15, no. 4: 138-147. 